OPEN ACCESS

Edited by:

Andressa Oliveira De Lima, São Paulo State University, Brazil

Reviewed by:

Juliana Afonso,

University of São Paulo, Brazi

Rajwali Khan,

University of Agriculture, Pakistan

*Correspondence:

Linsen Zan

zanlinsen@163.com

Specialty section:

This article was submitted to

Livestock Genomics,

a section of the journal

Frontiers in Genetics

Received: 01 December 2020

Accepted: 04 January 2021

Published: 03 February 2021

Citation

Chen X, Raza SHA, Ma X, Wang J,

Wang $X$, Liang $C$, Yang $X$, Mei $C$

Suhail SM and Zan L (2021) Bovine

Pre-adipocyte Adipogenesis is Regulated by bta-miR-150 Through mTOR Signaling

Front. Genet. 12:636550.

doi: 10.3389/fgene.2021.636550

\section{Bovine Pre-adipocyte Adipogenesis Is Regulated by bta-miR-150 Through mTOR Signaling}

\author{
Xingyi Chen ${ }^{1}$, Sayed Haidar Abbas Raza ${ }^{1}$, Xinhao Ma ${ }^{1}$, Jiangfang Wang ${ }^{1}$, Xiaohui Wang ${ }^{1}$, \\ Chengcheng Liang ${ }^{1}$, Xinran Yang ${ }^{1}$, Chugang Mei ${ }^{1}$, Syed Muhammad Suhail ${ }^{2}$ and \\ Linsen Zan ${ }^{1,3 *}$ \\ ${ }^{1}$ College of Animal Science and Technology, Northwest A\&F University, Xianyang, China, ${ }^{2}$ Department of Livestock \\ Management, Breeding and Genetics, The University of Agriculture, Peshawar, Pakistan, ${ }^{3}$ National Beef Cattle Improvement \\ Center, Northwest A\&F University, Xianyang, China
}

Micro RNA (miR) are recognized for their important roles in biological processes, particularly in regulatory componentization. Among the miR, miR-150 has been the focus of intense scrutiny, mostly due to its role in malignant tumors. A comparison between steer and bull adipose tissues identified bta-miR-150 as one of the nine downregulated miRNAs, although its function remains unknown (GEO:GSE75063). The present study aimed to further characterize the role of bta-miR-150 in cattle. bta-miR-150 has a negative regulatory effect on the differentiation of bovine adipocytes and promotes proliferation. Overexpression of bta-miR-150 can promote mRNA and protein expression of the marker genes CDK1,CDK2, and PCNA, increase the number of EdU-stained cells, promote adipocyte proliferation, inhibit adipocyte differentiation, and reduce lipid droplet formation. Results of RNA-seq and WGCNA analyses showed that the mammalian target of the rapamycin signaling pathway, which plays a major regulatory role, is dysregulated by the overexpression and inhibition of miR-150. We found that the target gene of bta-miR-150 is AKT1 and that bta-miR-150 affects AKT1 phosphorylation levels. These results showed that bta-miR-150 plays a role in adipogenic differentiation and might therefore have applications in the beef industry.

Keywords: bta-miR-150, mTOR, RNA-seq, adipocyte differentiation, WGCNA

\section{INTRODUCTION}

Adipose tissue that differentiates from mesenchymal stem cells during the embryonic period is responsible for many functions, including energy storage, lipid metabolism, and hormone secretion (Ambele et al., 2020; Poklukar et al., 2020). Since the amount of adipose tissue in meat impacts the economic value of animals, understanding the molecular mechanisms underlying adipose tissue generation in animals will ensure that production is maximized within an appropriate range. MicroRNA are non-coding RNA with a maturity length of 18-25 nt; they are ubiquitous in the animal kingdom and are produced by RNA polymerase II transcription. MicroRNA are involved in many different physiological processes in animals (Raza et al., 2020), including inhibition of the translation of target genes, affecting mRNA degradation, and regulating the transcription of target genes (Twayana et al., 2013). Differentiation of adipocytes is regulated by many miRNA, which are the focus of the current investigation. Advancements to high-throughput sequencing technology 
has allowed deeper exploration of cellular regulatory processes (Katz et al., 2010). Previous studies have already revealed the regulatory effects of human miRNA, including miR-204 (Zhang Z. et al., 2020), miR-27a (Kim et al., 2010), miR-210 (Ren et al., 2020), miR-24 (Liu et al., 2020), miR-378 (Duarte et al., 2020), miR-149-5p (Khan et al., 2020), miR-143 (Zhang L. et al., 2020), and miR-145 (Wang et al., 2020), on adipogenesis. These classic mechanisms also occur in the adipose tissue, where they have a large impact on the surrounding tissue (Arcidiacono et al., 2020; Raza et al., 2020). For example, miR-143 promotes the differentiation of adipocytes by directly acting on its target gene, MAP2K5. Many biologically significant miRNA have been discovered, with high-throughput sequencing technology continuously improving in parallel with a reduction in cost (An et al., 2016).

Because of its high expression level in immune-related cells, hsa-miR-150 was one of the first miRNAs to be studied in humans. Human (hsa)-miR-150 plays an important role in the differentiation of hematopoietic cell lines; thus, investigations of hsa-miR-150 have mainly focused on malignant tumors (Yugawa et al., 2020). In animal, miR-150 has been implicated in the mTOR pathway, where it regulates the expression of leptin in adipocytes (Scrutinio et al., 2017) and the production of lipids such as triglycerides (TGs) and free fatty acids (FFAs). The master metabolic factor PGC-1a mediates the reciprocating cycle between TG and FFA to achieve physiologically stable energy consumption (Kang et al., 2018). In pigs, ssc-miR-150 is differentially regulated in the adipose tissue miRNA of lean, rather than fatty pig breeds. Ssc-miR-150 is thought to act directly on the 3/UTR of CYP3A4 to promote FFA-induced adipose tissue degeneration (Ma et al., 2020). Since miRNA is highly conserved in the animal kingdom, bta-miR-150 might also function in the production of adipose tissue in cattle. Importantly, bta-miR-150 is one of the nine downregulated miRNA among differential expression profiles of steer and bull fat tissues (Liang et al., 2019).

With the global increase in human population and improvements in living standards, beef fat is increasingly being valued by breeders for the flavor it imparts, as well as its high energy value as a food source (Lillehammer et al., 2011). The 480-amino-acid enzyme, RAC-alpha serine/threonine-protein kinase (AKT1), located downstream of the mammalian target of the rapamycin signaling (mTOR) pathway regulates the growth of mammalian cells and is an important protein for regulating fat deposition (Zhang et al., 2017; Song et al., 2018). In mice, miR-150 inhibits AKT1. Bovine chromosome 21 encodes $A K T 1$, which is an important member of the PI3K/AKT/mTOR pathway. The activity of $A K T$ requires phosphorylation at Thr308 and is further enhanced by phosphorylation at Ser473. When Ser473 is simultaneously phosphorylated by PDK1 and mTORc2, AKT1 further regulates cell proliferation through downstream FOXO transcription factors and p53 regulatory factors (Cai et al., 2019; Sanchez-Gurmaches et al., 2019; Du et al., 2020) The present study aimed to determine the relationship between bta-miR-150 and $A K T 1$ by examining the effects and mechanisms of bta-miR-150 in regulating the proliferation and differentiation of Qinchuan beef cattle pre-adipocytes, thus providing a basis for targeted breeding and genetic improvement based on bta-miR-150. In beef cattle, the process of breeding to increase the intramuscular fat content would be supported by an understanding of the genetic basis of adipogenesis. Our research further clarifies the relationship between bta-miR-150 and adipocyte differentiation in cattle. This information paves the way for further research to expand our understanding of the complex process of adipocyte differentiation and adipose tissue generation.

\section{MATERIALS AND METHODS}

\section{Isolation of Primary Bovine Pre-adipocytes and Cell Culture}

The tissue and cell samples used in the experiment in this study were collected from three 1-day-old healthy Qinchuan cattle bulls with consistent growth bred from the National Beef Cattle Improvement Center of Northwest Agriculture and Forestry University (Yangling, China). Bacteria surgical instruments collected tissue samples such as heart, liver, spleen, lung, and muscle. The sample was placed in a sterile, DNase- and RNase-free cell cryotube. Then the sample was immediately put in liquid nitrogen for freezing, and finally stored in a refrigerator at $-80^{\circ} \mathrm{C}$ for later use.

We used 1-day-old healthy bulls to isolate the original bovine pre-adipocytes, removed the adipose tissue from different parts under aseptic conditions, washed with PBS supplemented with $10 \%$ antibiotics (penicillin/streptomycin) 3 times, and then added I Collagenase digestion for $1-2 \mathrm{~h}$ in a $37^{\circ} \mathrm{C}$ water bath shaker. After digestion, the cells were filtered with a cell sieve and the supernatant was discarded after centrifugation. The red blood cell lysate was added for lysis, and then an appropriate amount of DMEM-F12 (Gibco, Grand Island, NY) medium containing 10\% fetal bovine serum (FBS, Invitrogen) was added to resuspend the cells for seeding for subsequent experiments. The cells used in this experiment were all the 3rd generation cells after passage.

\section{Construction and Transfection of Plasmid and RNA Oligonucleotides}

The cells were inoculated in DMEM-F12 supplemented with $10 \%$ FBS and $1 \%$ antibiotics and kept continuously at $37^{\circ} \mathrm{C}$ and $5 \% \mathrm{CO}_{2}$. According to the manufacturer's instructions, the miR-150 mimic (50 nM), miR-150 mimic NC (50 nm), miR150 inhibitor $(100 \mathrm{nM})$, miR-150 inhibitor $\mathrm{NC}(100 \mathrm{nM})$, siAKT1 (100 nM), and si-NC were transfected into the cells using Lipofectamine $^{\text {TM }} 3000$ (Invitrogen, San Diego, GA, LUSA). We induced differentiation of adipocytes $48 \mathrm{~h}$ after transfection. After 2 days of induction with DMI $(0.5 \mathrm{~mm}$ IBMX, $1 \mu \mathrm{m}$ DXMS, and $2 \mu \mathrm{m}$ insulin) induction solution, we changed to a maintenance medium containing $5 \mu \mathrm{g} / \mathrm{mL}$ insulin. After differentiation induction, adipocytes were harvested at $\mathrm{d} 0, \mathrm{~d} 2, \mathrm{~d} 4$, $\mathrm{d} 6, \mathrm{~d} 8$, and $\mathrm{d} 10$. (We recorded the day of adding DMI as day 0 of induction of differentiation). Two restriction enzymes (Takara, Beijing, China), XhoI and NotI, were used to construct the vector psiCHECK-2(Laboratory retention). The detailed sequence is shown in Table 1. The Bta-miR-150 mimic, mimic NC, inhibitor, and inhibitor $\mathrm{NC}$ used in this stage were purchased from 
TABLE 1 | The sequence of RNA oligonucleotides and plasmid.

\begin{tabular}{|c|c|}
\hline Name & Sequence $\left(5^{\prime}-3^{\prime}\right)$ \\
\hline miR-150 mimic & $\begin{array}{l}\text { sense: UCUCCCAACCCUUGUACCAGUGU } \\
\text { antisense: ACACUGGTACAAGGGUUGGGAGA }\end{array}$ \\
\hline mimic NC & UUGUACUACACAAAAGUACUG \\
\hline miR-150 inhibitor & ACACUGGUACAAGGGUUGGGAGA \\
\hline inhibitor NC & CAGUACUUUUGUGUAGUACAA \\
\hline si-AKT1 & $\begin{array}{l}\text { sense: GCCAUGAAGAUCCUAAAGATT } \\
\text { antisense: UCUUUAGGAUCUUCAUGGCTT }\end{array}$ \\
\hline si-NC & $\begin{array}{l}\text { sense: UUCUCCGAACGUGCACGUTT } \\
\text { antisense: ACGUGACACGUUCGGAGAATT }\end{array}$ \\
\hline psiCHECK-2 & $\begin{array}{l}\text { 5'... GAGCAGTAATTCTAGGCGATCGCTCGAGCCCG } \\
\text { GGAATTCGTTAAACCTAGAGCGGCCGCTGGCCGC } \\
\text { AATAAAATA... } 3^{\prime}\end{array}$ \\
\hline
\end{tabular}

RiboBio, Guangzhou, China; the si- $A K T 1$ and si-NC used in this stage were purchased from GenePharma, Shanghai, China. The detailed sequence in is shown Table 1.

\section{Differential Expression and Pathway Enrichment Analyses}

Transfected miR-150 mimic, mimic NC, inhibitor, inhibitor NC, and bovine adipocytes were used to induce differentiation, and RNA on day 2 and day 6 were collected. A control was set for each treatment, with three technical replicates per group and a total of eight groups (24 samples). After RNA extraction, the HiSeq-PE150 platform (Illumina, Sandiego, CA, USA) was used for RNA sequence analysis. After filtering the original data, the reads were matched to the bovine genome using HiSat2 (Bos-taurusUMD3.1, release94, Ensembl database), and feature counts were used to count gene expression. The DESeq2 R software package was used to screen DEGs, with $\log _{2}$ fold change $\left(\log _{2} \mathrm{FC}\right)>1$ and false discovery rate $(\mathrm{FDR})<0.05$ as the screening criteria. ClusterProfiler was used to realize KEGG pathway analysis and FDR $<0.05$ was considered significant.

\section{Extraction of RNA, Quantitative Real-Time PCR (qRT-PCR)}

After $48 \mathrm{~h}$ of transfection, we used the RNAiso Plus Kit (Trizol, Takara, Beijing, China) to extract RNA. The specific extraction method can refer to the reference (Junjvlieke et al., 2020). After we removed the culture medium from the cells, we washed the cells with PBS 2 3 times in each well, then added $1 \mathrm{~mL}$ Trizol, placed the mixture at $4^{\circ}$ for $4 \mathrm{~min}$, and transferred the mixture to a $1.5 \mathrm{~mL}$ centrifuge tube. Two hundred microliters of chloroform was added to the centrifuge tube, shaken vigorously for $30 \mathrm{~s}$, left to stand for $5 \mathrm{~min}$, and centrifuged for $15 \mathrm{~min}$. The supernatant was then taken ( 3 layers in total), isopropanol was added, mixed upside down, left to stand on ice for $10 \mathrm{~min}$, and then centrifuged for $10 \mathrm{~min}$. After centrifugation, add $1 \mathrm{~mL}$ of $75 \%$ cold ethanol was slowly added to a small amount of precipitation at the bottom, centrifuged at $4^{\circ} \mathrm{C}$ for $5 \mathrm{~min}$, and then the ethanol was discarded. The cells were dried for 2-5 min at room temperature, then an appropriate amount of RNase-free DEPC water was added to dissolve the precipitate. NanoQuant plateTM (TECAN, Infinite M200 PRO) was used to determine the concentration and purity of RNA, and it was stored at $-80^{\circ} \mathrm{C}$ for later use. The method of extracting total RNA in tissues was to take out about $0.5 \mathrm{~g}$ tissue sample in a refrigerator at $-80^{\circ} \mathrm{C}$, add it to liquid nitrogen for pre-cooling, and then place it in a mortar cooled with liquid nitrogen for grinding. After grinding, the sample is transferred to a $1.5 \mathrm{~mL}$ enzyme-free centrifuge tube with $1 \mathrm{~mL}$ Trizol, and then placed on ice for $15 \mathrm{~min}$. The next step is the same as that of extracting cellular RNA.

Reverse transcription of total RNA was performed following Prime Script TM RT reagent Kit with gDNA Eraser (Takara, China), TB Green ${ }^{\circledR}$ Premix Ex TaqTM II(TAKARA, Beijing, China) instructions. The reverse transcription and qPCR of miRNA were performed with miRcute Plus miRNA FirstStrand cDNA Kit and miRNA Plus miRNA qPCR Kit (SYBR Green) (Tiangen, Beijing, China). U6 and $\beta$ - actin was used as the internal control for miRNA quantification and mRNA quantification, respectively. The sequence of all PCR primers is shown in Table 2. All experiments were performed with three biological replicates and three technical replicates. The $2-\Delta \Delta \mathrm{Ct}$ method was used to analyze the relative expression levels of different qPT-PCR data.

\section{Western Blot Analysis}

The methods of extraction and Western blot analysis of total protein have been introduced in references (Khan et al., 2019; Wang et al., 2019). The protein bands added with Millipore chemiluminescence solution were placed on the Gel DocTMXR+ System (Bio-Rad, Hercules, CA) for exposure imaging. The antibody in Table 3 is the antibody we used in the experiment.

\section{EdU Staining and CCK-8 Assay}

The Qinchuan cattle pre-adipocytes were seeded in a 96-well plate (NEST, Jiang Su, China) and cultured to a density of 40$60 \%$ confluence, which was reached at a density of $5.0 \times 10^{4}$ cells for transfection. The specific processing steps are detailed in reference (Chu et al., 2019). We added $100 \mu \mathrm{L}$ PBS to each well of the last stained cells and washed them 1 to 3 times, and then took photographs under a microscope. The instrument used for taking pictures was an Olympus $1 \times 71$ microscope (Olympus, Tokyo, Japan). The treatment method of CCK-8 cell cycle detection was the same as that of EdU. The specific operation steps were carried out according to the reference (Khan et al., 2020). The kit used was TransDetect Cell Counting Kit (Transgen biotechnology, Beijing, China), and the detection instrument was an Infinite ${ }^{\circledR} 200$ PRO (Tecan Trading AG, Switzerland).

\section{Bodipy, Oil Red O Staining, and Triacylglycerol Assay}

The differentiated cells were stained for different days. The cells on the second day were stained with Bodipy, and the cells on the fourth and sixth days were stained with oil red O. In short, both Bodipy $(1: 1,000)$ and DAPI $(1: 1,000)$ were diluted in PBS. The cells to be stained were washed with PBS 3 times, fixed with $4 \%$ paraformaldehyde for $30 \mathrm{~min}$, and then stained with Bodipy for 30 min. After staining, the cells were washed with PBS 3 times 
TABLE 2 | mRNA and miRNA Real-time quantitative PCR primer sequences.

\begin{tabular}{|c|c|c|}
\hline Genes & Primer Sequence $\left(5^{\prime}-3^{\prime}\right)$ & $\begin{array}{l}\text { Annealing } \\
\text { temperature }\end{array}$ \\
\hline$\beta$-actin & $\begin{array}{l}\text { F: CATCGGCAATGAGCGGTTCC } \\
\text { R: CCGTGTTGGCGTAGAGGTC }\end{array}$ & $60^{\circ} \mathrm{C}$ \\
\hline PCNA & $\begin{array}{l}\text { F: CCTTGGTGCAGCTAACCCTT } \\
\text { R: TTGGACATGCTGGTGAGGTT }\end{array}$ & $60^{\circ} \mathrm{C}$ \\
\hline CDK1 & $\begin{array}{l}\text { F:AGTGGAAACCAGGAAGCTTAG } \\
\text { R:ATTCGTTGGCAGGATCATAGA }\end{array}$ & $60^{\circ} \mathrm{C}$ \\
\hline CDK2 & $\begin{array}{l}\text { F:GGGTCCCTGTTCGTACTTATAC } \\
\text { R:CCACTGCTGTGGAGTAGTATIT }\end{array}$ & $60^{\circ} \mathrm{C}$ \\
\hline AKT-1 & $\begin{array}{l}\text { F:AAGGAGATCATGCAGCACCGATTC } \\
\text { R: GTCTTGGTCAGGTGGCGTAATGG }\end{array}$ & $60^{\circ} \mathrm{C}$ \\
\hline $\mathrm{CEBP} \alpha$ & $\begin{array}{l}\text { F: ATCTGCGAACACGAGACG } \\
\text { R: CCAGGAACTCGTCGTTGAA }\end{array}$ & $60^{\circ} \mathrm{C}$ \\
\hline PPAR $\gamma$ & $\begin{array}{l}\text { F: GACGACAGACAAATCACCGT } \\
\text { R: CTTCCACGGAGCGAAACTGA }\end{array}$ & $60^{\circ} \mathrm{C}$ \\
\hline FABP4 & $\begin{array}{l}\text { F:TGAGATTTCCTTCAAATTGGG } \\
\text { R: CTTGTACCAGAGCACCTTCATC }\end{array}$ & $60^{\circ} \mathrm{C}$ \\
\hline RRAGD & $\begin{array}{l}\text { F: TAAGAAGGAGCGGCAAGT } \\
\text { R: GGAAGTCCCAAATCTGAAA }\end{array}$ & $60^{\circ} \mathrm{C}$ \\
\hline RPS6KA3 & $\begin{array}{l}\text { F:ACCTAGCAACATTCTTTATGTGGAT } \\
\text { R: GCATCATAGCCTTGTCGT }\end{array}$ & $60^{\circ} \mathrm{C}$ \\
\hline RPS6KB1 & $\begin{array}{l}\text { F: ATCACCAAGGTCACGTCAAAC } \\
\text { R: TGCTCCCAAACTCCACCAAT }\end{array}$ & $60^{\circ} \mathrm{C}$ \\
\hline LPIN1 & $\begin{array}{l}\text { F: AGTGAATCTTCAGATGCGTTAA } \\
\text { R: CAGGTGTCGGCTTCGTाT }\end{array}$ & $60^{\circ} \mathrm{C}$ \\
\hline NFKB1 & $\begin{array}{l}\text { F: GAGAACTTCGAGCCTCTGTAC } \\
\text { R: CTCATAGGGTTCCCATTA }\end{array}$ & $60^{\circ} \mathrm{C}$ \\
\hline ElF4E & $\begin{array}{l}\text { F: TCTAATCAGGAGGTTGCT } \\
\text { R: CCCACATAGGCTCAATAC }\end{array}$ & $60^{\circ} \mathrm{C}$ \\
\hline PIK3CA & $\begin{array}{l}\text { F:TGGGTTCTCGGTCCTAA } \\
\text { R:CAGTCCGTCCAGTCATCC }\end{array}$ & $60^{\circ} \mathrm{C}$ \\
\hline TNFRSF1B & $\begin{array}{l}\text { F: CCAGCACAGCTCCAAGCA } \\
\text { R:CAACTATCAGAAGCAGACCCAAT }\end{array}$ & $60^{\circ} \mathrm{C}$ \\
\hline INSR & $\begin{array}{l}\text { F: GGAAGGCGAGAAGACCAT } \\
\text { R: TGACACCAGGGCATAGGA }\end{array}$ & $60^{\circ} \mathrm{C}$ \\
\hline EIF4EBP2 & $\begin{array}{l}\text { F: GTTCCTGATGGAGTGTCGGA } \\
\text { R: AACTGTGACTCTTCACCGCCT }\end{array}$ & $60^{\circ} \mathrm{C}$ \\
\hline PIK3R1 & $\begin{array}{l}\text { F: GAGCGGGAAGAGGACATTGA } \\
\text { R: TCTCCCCTGTCGTCTCGTTA }\end{array}$ & $60^{\circ} \mathrm{C}$ \\
\hline mTOR & $\begin{array}{l}\text { F: TGATGCAGAAGGTCGAGGTG } \\
\text { R: GATGGGTGTCTATCGCCCAG }\end{array}$ & $60^{\circ} \mathrm{C}$ \\
\hline PIK3R1 & $\begin{array}{l}\text { F: CTATCTCCTGGACTTACCG } \\
\text { R: GGCGACCTAATGAGTTTC }\end{array}$ & $60^{\circ} \mathrm{C}$ \\
\hline U6 & $\begin{array}{l}\text { F:TAGCCACCCTCAAGTATGTTCG } \\
\text { R:CGAGGTAGGAGGACAGGAGT }\end{array}$ & $60^{\circ} \mathrm{C}$ \\
\hline miR-150 & UCUCCCAACCCUUGUACCAGUGU & $60^{\circ} \mathrm{C}$ \\
\hline
\end{tabular}

and then stained with DAPI. Finally, the cells were photographed under a microscope. The whole process needs to be done away from light.

The oil red $\mathrm{O}$ staining procedure was as follows: the cells were washed in the six-well plate with PBS 3 times, fixed with $4 \%$ paraformaldehyde for $30 \mathrm{~min}$, dyed with $60 \%$ oil red $\mathrm{O}$ (solvent: isopropanol, $0.15 \mathrm{~g}$ oil red powder $/ 100 \mathrm{~mL}$ ) for $30 \mathrm{~min}$,
TABLE 3 | Antibody information.

\begin{tabular}{lllc}
\hline Name of antibody & Immune features & $\begin{array}{l}\text { The } \\
\text { company }\end{array}$ & Dilution ratio \\
\hline Anti-AKT1 antibody & Rabbit polyclonal & CST & $1: 1,000$ \\
Phospho-Akt (Ser473) antibody & Rabbit polyclonal & CST & $1: 1,000$ \\
Anti-CDK1 antibody & Rabbit monoclonal & Abcam & $1: 1,000$ \\
Anti-CDK2 antibody & Rabbit monoclonal & Abcam & $1: 1,000$ \\
Anti-PCNA antibody & Rabbit monoclonal & Abcam & $1: 5,000$ \\
Anti-PPAR antibody & Rabbit polyclonal & Boster & $1: 1,000$ \\
Anti-FABP4 antibody & Rabbit monoclonal & Abcam & $1: 1,000$ \\
Anti-CEBP $\alpha$ antibody & Rabbit monoclonal & Abcam & $1: 1,000$ \\
Anti- $\beta$-actin antibody & Rabbit polyclonal & Abcam & $1: 10,000$ \\
\hline
\end{tabular}

then washed with PBS and observed under a microscope. We measured the amount of intracellular TAG using the cell/tissue triglyceride assay kit (Applygen Technologies, Beijing, China) according to the protocol recommended by the manufacturer (Ma et al., 2018).

\section{Luciferase Reporter Assay}

To verify whether bta-miR-150 targets the 3'-UTR of AKT1, we obtained the mature sequence of bta-miR-150 from the miRBase (http://www.mirbase.org/). The reporter of luciferase was produced by ShengGong (Sangon Biotech Co., Ltd, Shanghai, China) through synthesizing 3'-UTR of AKT1 wild-type (WT) and mutation-type (MUT) of AKT1 sequence. Xhol and Notl cutting sites of Wt-3'-UTR containing miR-150 target were amplified. AKT1-3'UTR WT or MUT were cloned into psiCHECK-2 vector (Laboratory retention) by Xhol and Notl restriction sites (Promega, Madison, WI, USA). After culturing HEK293A cells for 2 days, they were then co-transfected into bovine adipocytes with about $0.16 \mu \mathrm{g}$ of MUT vector/AKT1$3^{\prime}$ UTR WT and 5 pmol miR-150 mimic/negative control. At $48 \mathrm{~h}$ after transfection, the luciferase activity was measured by Dual-Luciferase ${ }^{\circledR}$ Reporter Assay System (Promega, Madison, WI, USA). Luciferase assay was carried out in three repeat wells, and three experiments were carried out.

\section{Weighted Gene Co-expression Network Analysis (WGCNA)}

WGCNA, an R package, was used to construct the weighted gene co-expression network. With the standardized gene expression matrix as input, the variation degree of each gene expression level among samples was calculated, and the top 50\% genes with the largest variation were selected for WGCNA. After the threshold screening, the scaleless adjacency matrix was obtained by power processing with $\beta=12$. In order to better evaluate the correlation of gene expression patterns, the adjacency matrix was further transformed into a topological overlap matrix (ToM), and the dynamic cutting algorithm was used to cluster and partition genes by using the topological difference matrix (distom $=1$-tom). 


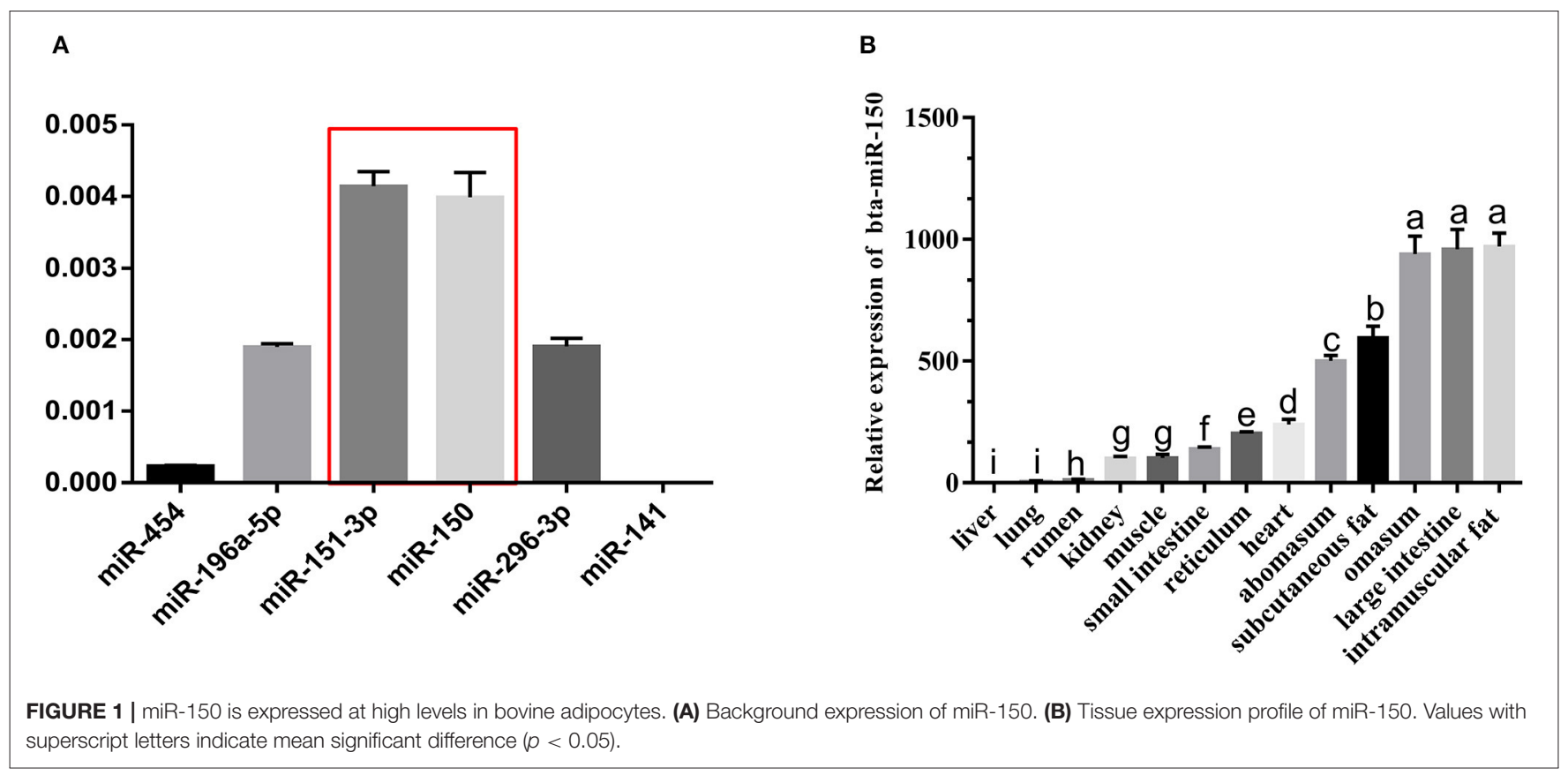

\section{Annotation of Gene Modules and KEGG Analysis}

In order to explore the biological function of gene modules, David and KOBAS online tools were used to analyze the gene go and KEGG enrichment to describe the function of the modules and identify the relationship between these modules. The $p$-value was adjusted by the Benjamin Hochberg method.

\section{Statistical Analysis}

Data are expressed as mean \pm SD. Statistical analysis was performed using SPSS 19.0 software (SPSS, Chicago, IL, USA) and GraphPad Prism 6. One-way ANOVA and Dunnett's multiple comparison test were used to analyze $P$-values. Student's $t$-test was used for comparative analysis of the two groups, and ${ }^{*} p<0.05,{ }^{* *} p<0.01,{ }^{* * *} p<0.001$ were considered statistically significant.

\section{RESULTS}

\section{miR-150 Is Up-Regulated in the Adipose Tissue From Qinchuan Cattle}

To initially screen for candidate miRNA that regulate the development of bovine adipose tissue, we selected 52 differentially expressed (DE) miRNA $\left(\log _{2}(\mathrm{FC})>1\right.$, FDR $<$ 0.05 ) based on our previous sequencing of transcriptomes from steers and bulls (GEO:GSE75063). Among these, 16 DE miRNA with sequence homology to human miRNA and their target DE genes (DEG) were assessed using Ingenuity Pathway Analysis (IPA) to construct a gene interaction network. In total, nine of these DE miRNA and 42 target DEG were mapped to a network that is involved in the differentiation of fat cells and fat tissue metabolism (Zhang et al., 2017). We tested background levels of miRNA with unknown or incomplete functional annotation by qPCR and found that background levels of miR-150 and miR-151-3p were higher than those of other miRNA in fatty tissues (Figure 1A), which was consistent with previous (Zhang et al., 2017). We therefore speculated that miR-150 is involved in the development and regulation of bovine adipose tissue (Figure 1B).

\section{Bovine Pre-adipocyte Proliferation Is Promoted by miR-150}

We transfected bovine pre-adipocytes with a miR-150 mimic, mimic NC, miR-150 inhibitor, and inhibitor NC to further explore the effects of miR-150 on the proliferation of bovine pre-adipocytes. We initially stained cells with EdU. At $48 \mathrm{~h}$ after transfection, the rate of EdU-positive cells was significantly higher among pre-adipocytes incubated with the bta-miR-150 mimic than with mimic NC $(p<0.05)$, and the rate of EdU-positive cells was significantly lower in cells transfected with bta-miR-150 inhibitor than with inhibitor $\mathrm{NC}(p<0.05)$ (Figures 2A,B). The results of CCK-8 assays were consistent with these findings (Figure 2C).

We then assessed changes in expression levels of proliferation marker genes at the mRNA and protein levels. Bovine preadipocytes were incubated for $48 \mathrm{~h}$ with mimic and inhibitor miR-150, and then, total RNA was extracted. The expression levels of genes associated with the cell cycle, such as CDK1 (cyclin dependent kinase1), CDK2 (cyclin dependent kinase2), and PCNA (proliferating cell nuclear antigen) significantly increased in cells incubated with the mimic and significantly decreased in those incubated with the inhibitor (Figures 2D1-D3) compared with that in the negative control. Western blotting showed 


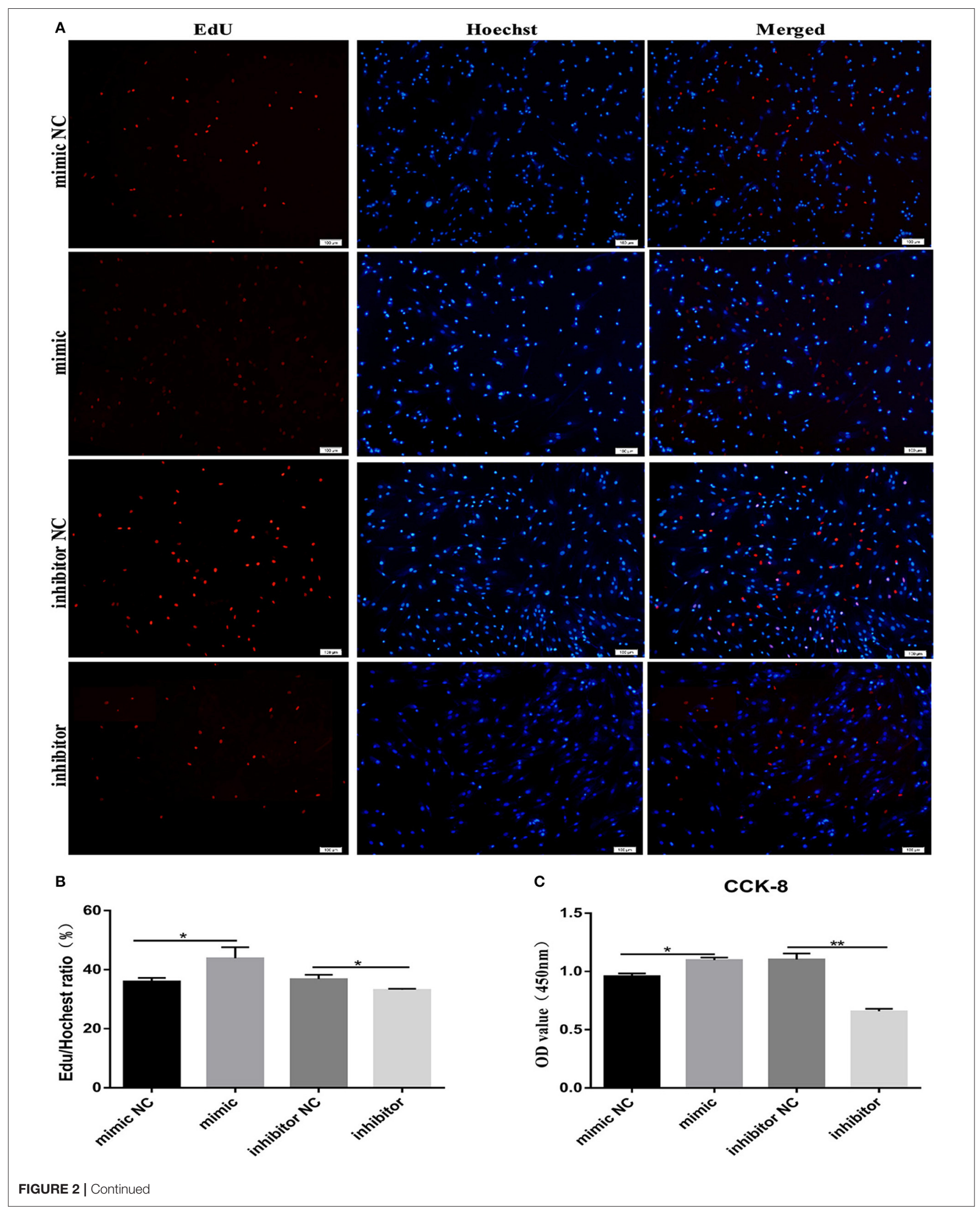




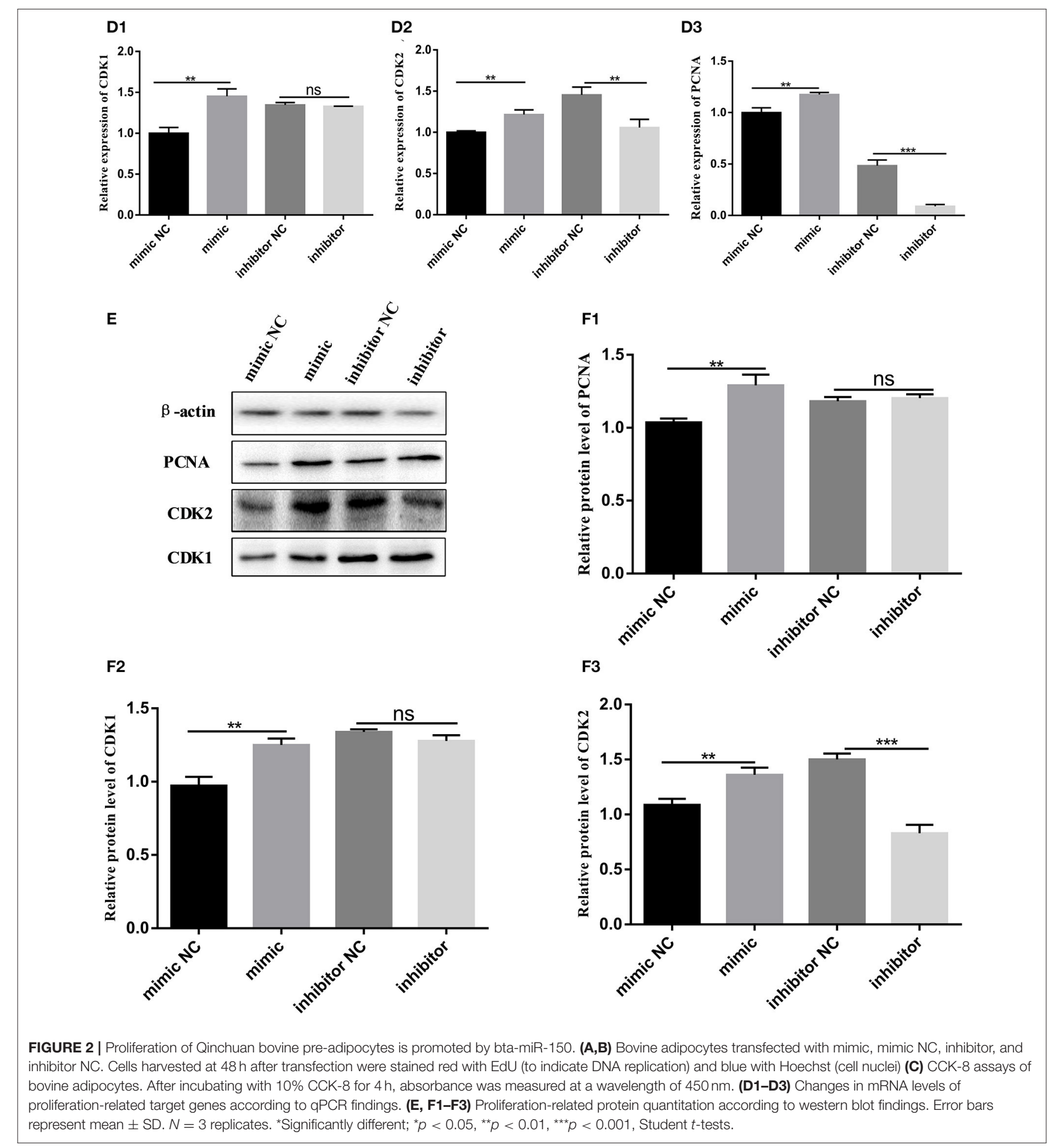

that proliferating pre-adipocytes incubated with mimic miR150 had significantly increased protein levels of CDK1, CDK2, and PCNA, while those incubated with miR-150 inhibitor had significantly reduced protein levels than the negative control (Figures 2E,F1-F3). These findings suggest that miR-150 promotes bovine pre-adipocyte proliferation.

\section{Inhibition of miR150 Promotes Adipogenesis}

Total RNA extracted from bovine normal adipocyte cells at 0,2 , $4,6,8$, and 10 days of induced differentiation in vitro, was reverse transcribed into cDNA. Quantitative PCR findings showed that miR-150 mRNA reached the highest level on day 2 of induced 

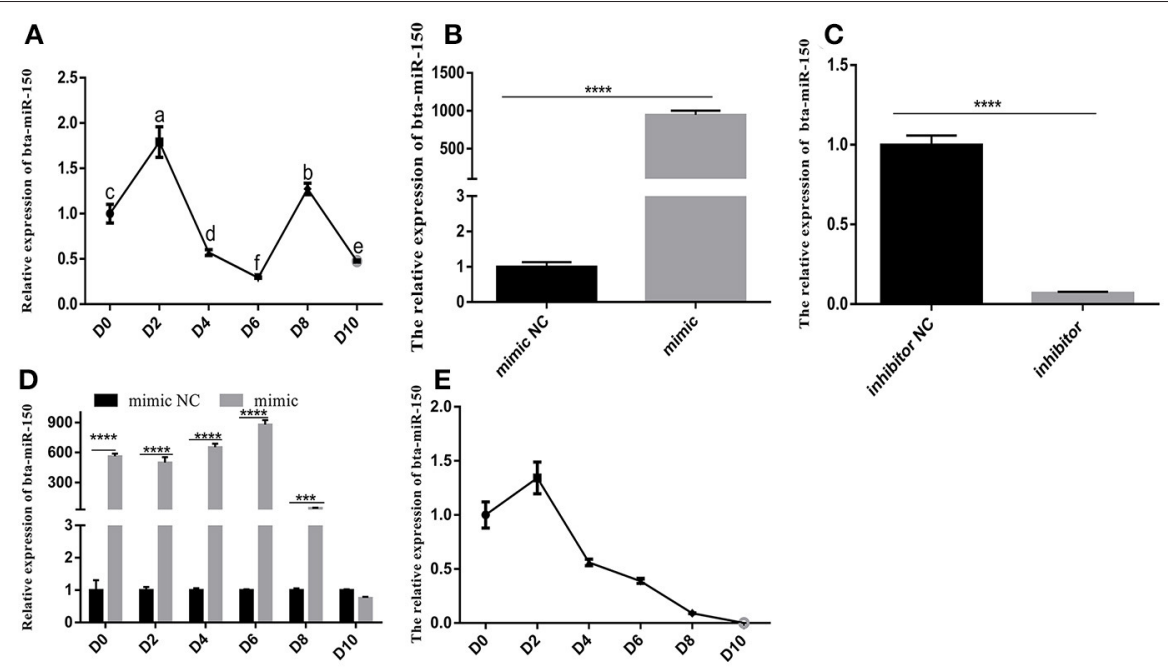

F1

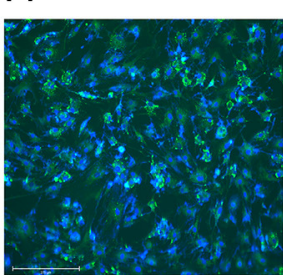

mimic NC

F2

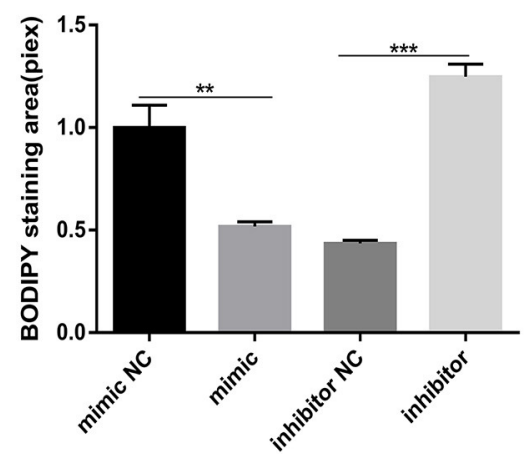

G2

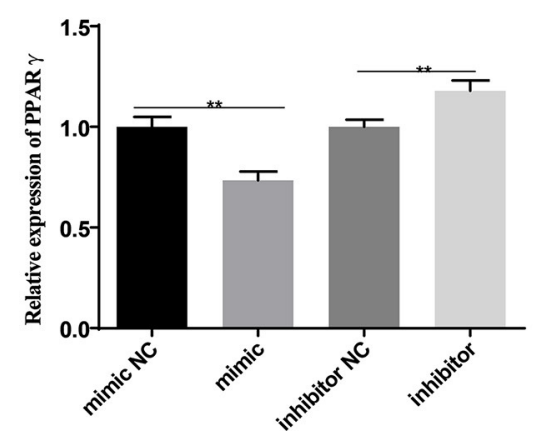

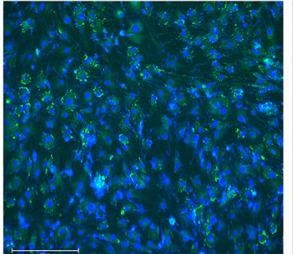

inhibitor NC

G1

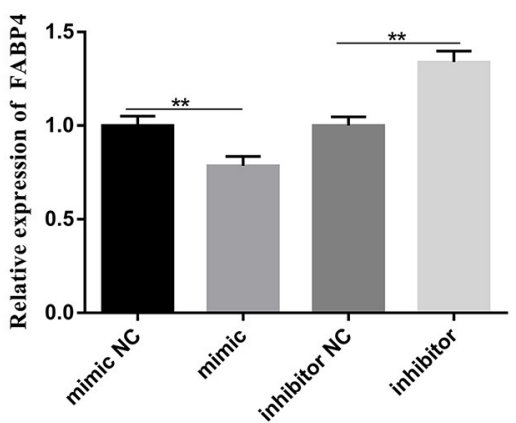

G3

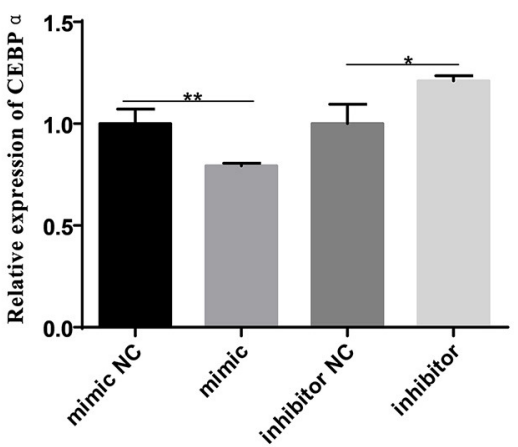




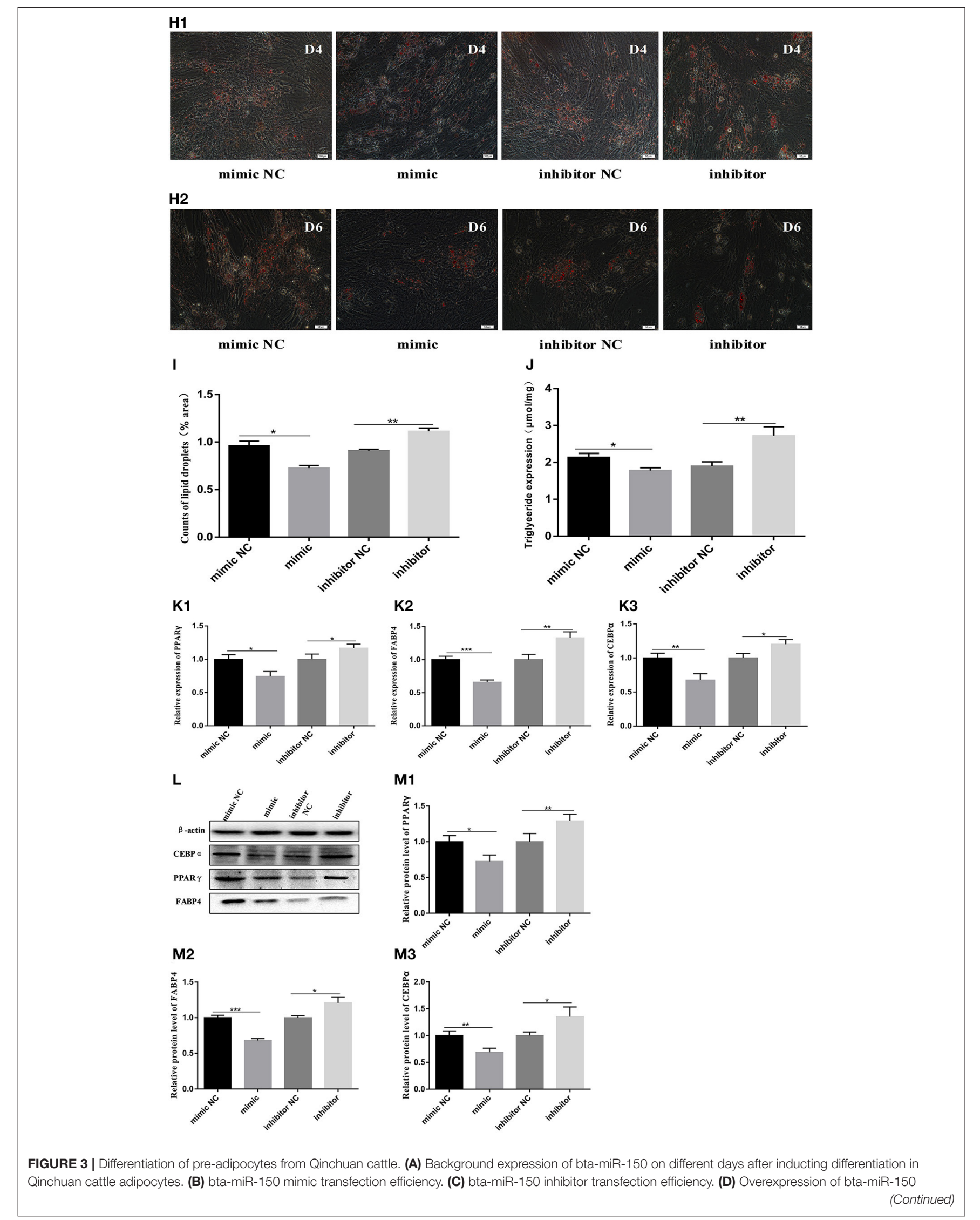


FIGURE 3 | treated with miR-150 mimic in 10 days. (E) Changes of bta-miR-150 content in Qinchuan cattle adipocytes treated with miR-150 mimics. (F1,F2) After transfection of miR-150 mimic, miR-150 inhibitor, or negative control, the adipocytes were stained with Bodipy and quantified on the second day of differentiation; photos were taken with an Evos-fl-auto2 automatic living cell fluorescence microscopy imaging system (Thermo Fisher, USA). (G1-G3) Changes in mRNA levels of adipose differentiation marker genes on the second day of differentiation (FABP4, PPAR $\gamma$, and CEBP $\alpha$ ). (H1) Oil red O staining of mimics, inhibitors, and their respective internal controls on day 4; the photos were taken with an Olympus Image IX71 microscope (Olympus, Japan). (H2) bta-miR-150 mimic treatment on day 6 , Oil red O staining of substances, inhibitors, and their respective internal controls; the photos were taken with an Olympus Image IX71 microscope (Olympus, Japan). (I) Statistics of lipid droplet content on day 4 of differentiation, using Image $\mathrm{J}$ software. (J) Triglyceride content on day 4 of differentiation. (K1-K3) Changes in mRNA levels of fat differentiation marker genes (FABP4, PPAR $\gamma$, CEBP $\alpha$ ) on the 4th day. (L) Protein map of fat differentiation marker genes (FABP4, PPAR $\gamma$, CEBP $\alpha$ ). (M1-M3) Quantitative processing of fat differentiation marker gene protein results (FABP4, PPAR $\gamma$, CEBP $\alpha$ ); protein levels were quantified and analyzed by Image $J$ software. Error bars represent mean \pm SD. $n=3$ replicates. ${ }^{*}$ denotes significance according to Student's $t$-test, ${ }^{\star} p<0.05,{ }^{\star \star} p<0.01,{ }^{\star \star \star *} p<0.001$, and ${ }^{\star \star \star \star} p<$ 0.0001.

differentiation in vitro, decreased to the lowest level on day 6 , started to increase briefly on day 8 , and then began to decline again (Figure 3A). Cells at $\sim 80 \%$ density were transfected, and transfection efficiency was measured $48 \mathrm{~h}$ later (Figures 3B,C). The effect of the bta-miR-150 mimic was prevalent until day 8 after transfection, but the bta-miR-150 content briefly reached a maximum on day 2 and then continuously fell (Figures 3D,E). We directly assessed the effects of miR-150 on adipose differentiation by staining lipid droplets using BODIPY and oil red O (Figures 3F1,F2,H1,H2). Compared with the control group, the number of lipid droplets in bta-miR-150 mimic-treated adipocytes decreased, while the number of lipid droplets significantly increased in adipocytes incubated with the inhibitor compared with the control. Overexpressed bta-miR150 significantly inhibited the TG production, which increased when bta-miR-150 was inhibited (Figure 3J). The mRNA and protein levels of peroxisome proliferator-activated receptor gamma $(P P A R \gamma)$, fatty acid binding protein 4 (FABP4), and CCAAT enhancer binding protein alpha $(C E B P \alpha)$ were higher with miR-150 inhibition compared with the levels with miR150 overexpression NC (Figures 3G1-G3,K1-K3). Inhibition of bta-miR-150 therefore promotes adipogenesis.

\section{GO and KEGG Analysis of Bovine Adipocyte DEG}

We further clarified the regulatory effect of miR-150 on the differentiation of bovine pre-adipocytes using RNA-seq. The miR-150 mimic, mimic NC, inhibitor, and inhibitor NC were transfected into bovine pre-adipocytes as described above, and cells were collected on days 2 and 6 after differentiation. The cells were then incubated daily with miR-150 mimic, mimic NC, inhibitor, and inhibitor NC. Transcriptomes from eight groups ( $n=3$ replicates per group) were sequenced (Beijing Novo Gene, Beijing, China) (Figure 4A). The RNA-seq results of cells transfected with miR-150 mimic, mimic NC, inhibitor, and inhibitor NC of D2, in which a total of 7,348 DEGs were detected, showed there were 1,234 common DEGs in four groups (Figure 4B). We identified the DEG in each group, then assessed them with the KEGG pathway and GO function enrichment analyses and WGCNA analysis (Figures 4C-F).

The soft threshold in the WGCNA analysis was set to 12, and 23 gene modules were detected (Figure 4G). By comparing different groups within the same modules, we identified five modules (green-yellow, light yellow, brown, blue, midnight blue). To better understand the biological function of specific gene modules related to the bovine adipocyte differentiation, we searched for DEG in these five modules using DAVID and KOBAS software using the key words, "fat fractionation" and "metabolism." We found enrichment for type II diabetes mellitus (ID: bta04930), the mTOR signaling pathway (bta04150), fatty acid degradation (ID: bta00071), and fatty acid metabolism (ID: bta001212) (Figures 4H,I). These pathways are all involved in the biological process of adipogenesis. We combined the RNAseq data with the WGCNA analysis of KEGG findings and comprehensively integrated $P$-values, numbers of genes changed in the pathway, and the mTOR pathway as main research channels $(P<0.05)$.

\section{The mTOR Signaling Pathway Is Regulated by bta-miR-150 Through AKT1}

We used targetscan7.1 to predict conserved target genes of miR-150 and the biological function of miR-150 during the development of bovine pre-adipocytes. We focused on the mTOR pathway based on the findings of the transcriptomic analysis (Figure 5A). Over $80 \%$ of the genes in the mTOR pathway were changed at the mRNA level by the miR-150 mimic or inhibitor (Figures 5B,C). Based on this and published information, we selected the adipocyte differentiation-related gene AKT1 as a candidate target of bta-miR-150. We then constructed two luciferase reporter vectors for wild-type AKT13/UTR and mutant $A K T 1$ 3/UTR (Figure 5D1). Dual luciferase reporter assays revealed that $A K T 1$ is a target gene of bta-miR-150 (Figure 5D2). To further confirm the relationship between bta-miR-150 and $A K T 1$, we measured $A K T 1$ expression during adipocyte differentiation at the mRNA and protein levels. The data indicated that bta-miR-150 promotes adipocyte differentiation by directly targeting $A K T 1$. Western blot results showed that $A K T 1$ phosphorylation increased throughout differentiation up to a maximum of 1.0 -fold after $48 \mathrm{~h}$, compared with that at $0 \mathrm{~h}$ (Figures 5E,F). Taken together, these results implicate $A K T 1$ in fat differentiation in cattle and that AKT1 is a target of bta-miR-150.

\section{si-AKT1 Can Inhibit Adipocyte Differentiation}

We used si-AKT1 interference to determine the role of $A K T 1$ in pre-adipocytes from Qinchuan beef cattle. We determined the optimal siRNA concentration required to ensure high knockout efficiency before transfection (Figures 6A-C). We then showed that silencing the $A K T 1$ gene with $100 \mathrm{nM}$ si-AKT1 reduced 


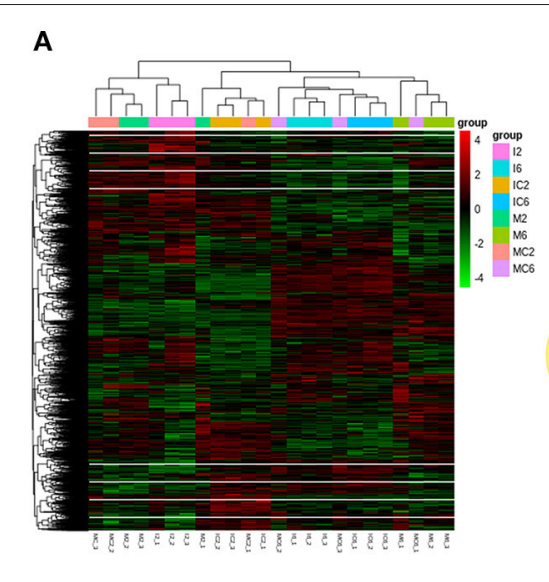

G

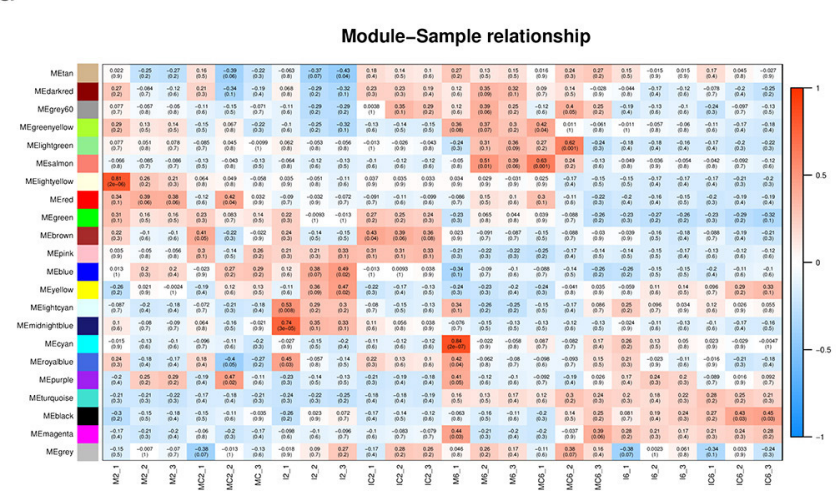

H

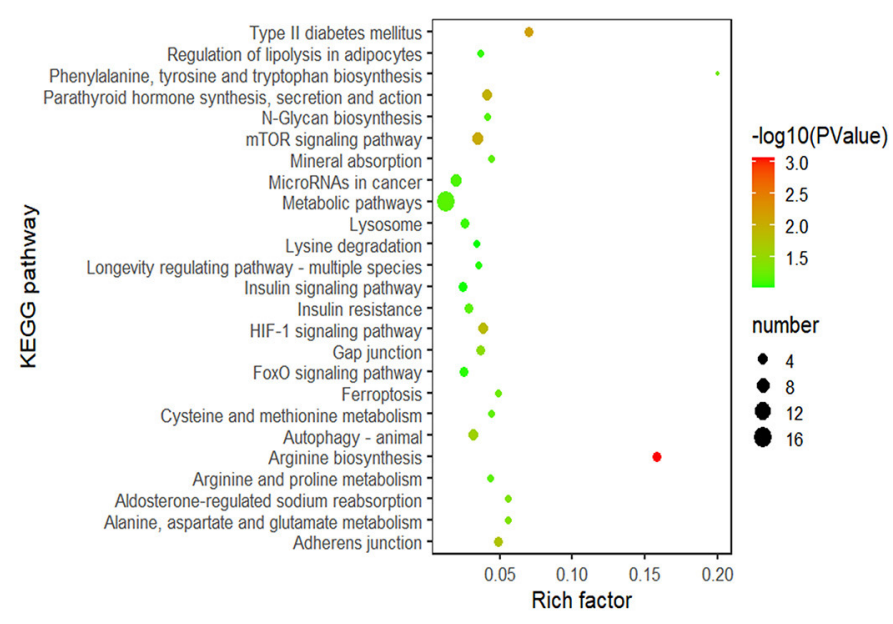

C

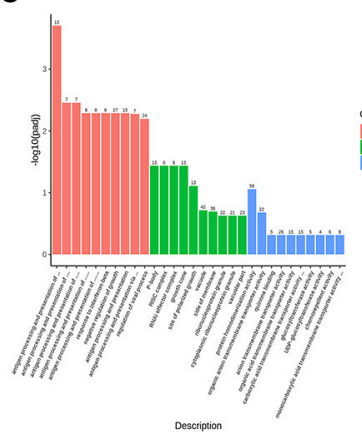

M2 VS MC2

E

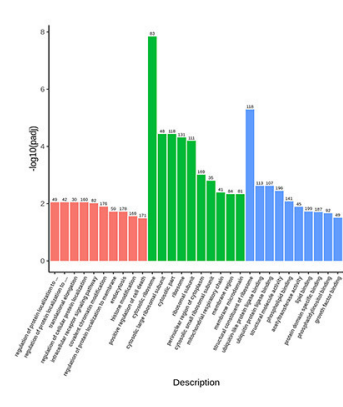

I2 vs IC2
D

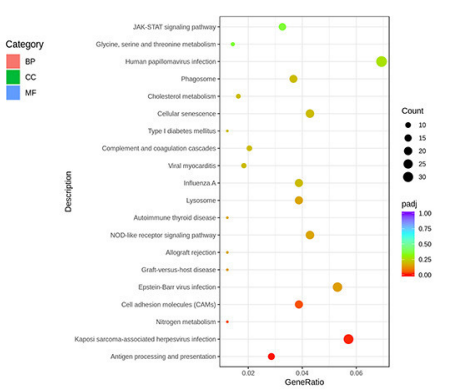

M2 VS MC2

F

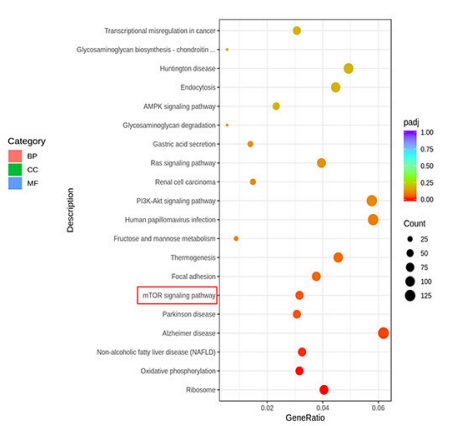

I2 vs IC2

I

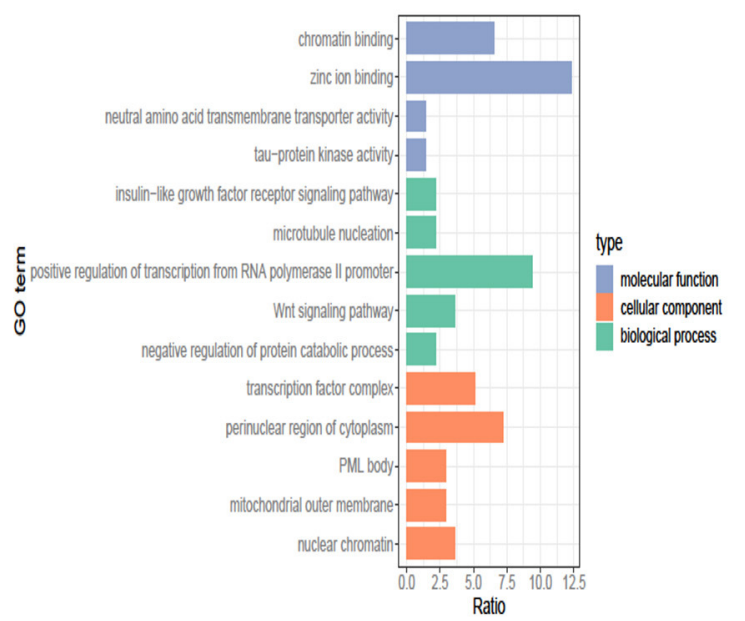

FIGURE 4 | GO and KEGG analysis of bovine adipocytes DEG and WGCNA analysis. (A) Differentially expressed gene clustering heat map. The abscissa is the sample name, and the ordinate is the normalized value of the differential gene FPKM. Red color indicates higher expression levels, while green represents lower expression levels; (B) The DEGs represented by a Venn diagram. Venn diagram showing the overlapping portion by sharing the expression pattern of the DEGs; (C) GO enrichment analysis of mimic treatment group and mimic NC group on the second day; (D) KEGG pathway enrichment analysis of mimic treatment group and mimic NC group on the second day;(E) GO enrichment analysis of inhibitor treatment group and inhibitor NC group on the second day; (F) KEGG pathway enrichment analysis of inhibitor treatment group and inhibitor NC group on the second day; (G) Correlation thermogram between samples and modules; (H) KEGG enrichment analysis of Midnightblue modules; (I) GO enrichment analysis of Midnightblue modules. 


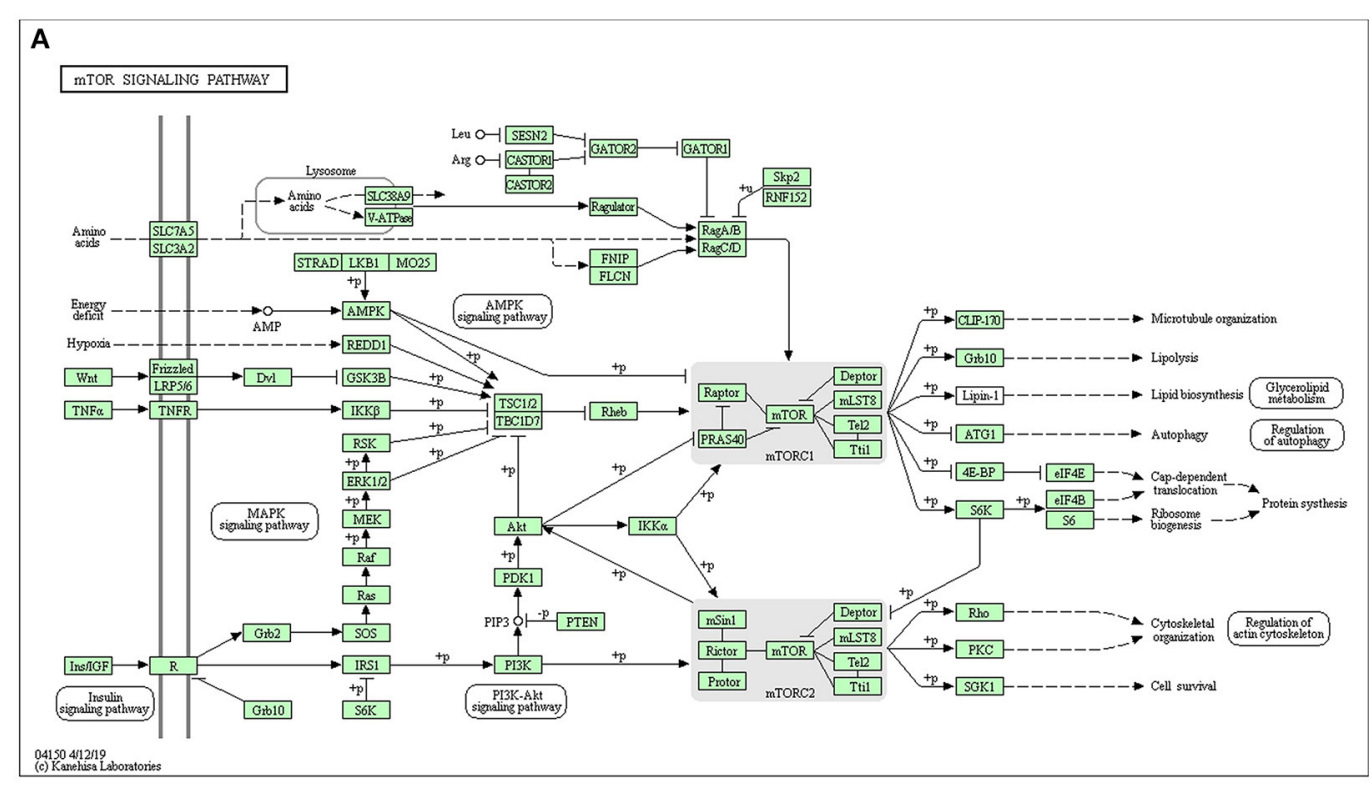

B

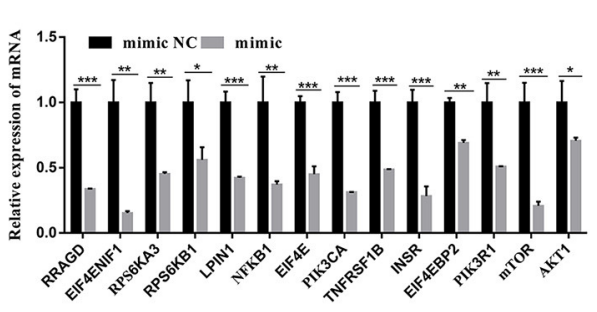

C

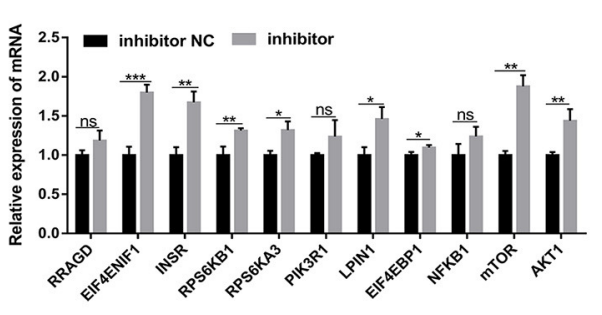

D1

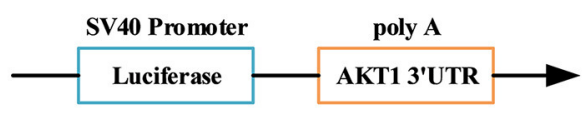

Bta-miR-150(cattle) ucucccaacccuuguaccagu Mmu-miR-150 (Mouse) ucucccaacccuuguaccagug Hsa-miR-150 (Human) ucucccaacccuuguaccagug Rno-miR-150 (Rat) ucucccaacccuuguaccagug Cfa-miR-150 (Dog) ucucceaacccuuguaccagug Ggo-miR-150 (Gorilla) ucuccaacccuuguaceagug

1682: 5' gacuagcacececggTGGGAGg 3' Wt AKT1 3' gugaccauguucceaACCCUÇu 5' bta-miR-150 5' gacuagcaccceggUGGCTGg Mut AKT1
E

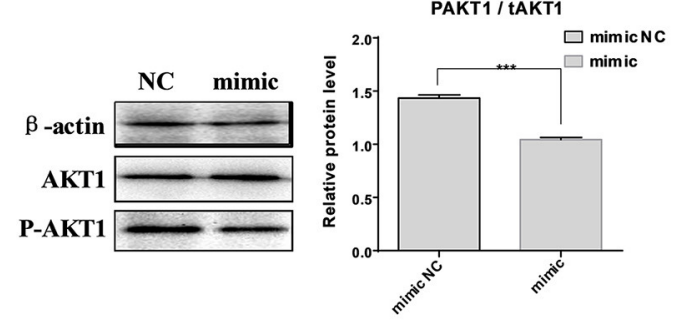

$\mathbf{F}$

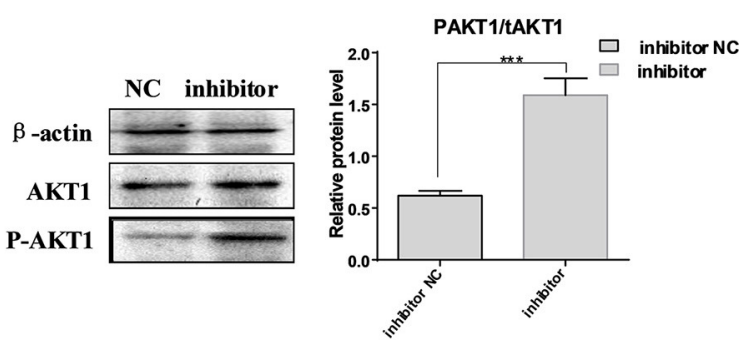

D2

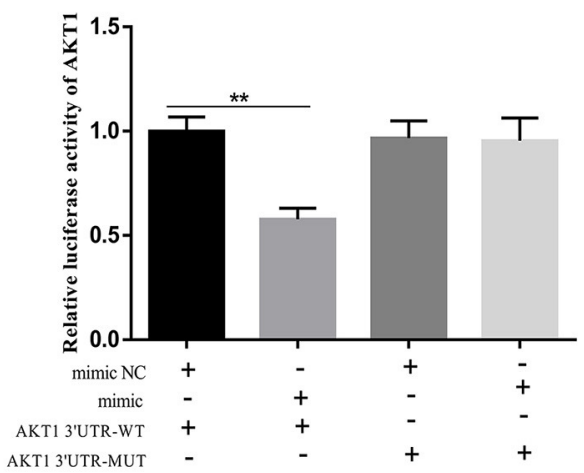

FIGURE 5 | bta-miR-150 directly targets AKT1 and regulates adipocyte differentiation through mTOR pathway. (A) mTOR signaling pathway. (B,C) Changes in mRNA levels in the mTOR pathway on day 2 after incubation with the mimic, inhibitor, and NC. (D1) Construction of a double luciferase reporter vector; (D2) Changes in luciferase activity after co-transfection. (E,F) Western blots of Akt1 phosphorylation on day 2 of differentiation. Error bars, means \pm SD. $n=3$ replicates. *denotes significance according to Student's $t$-test, ${ }^{*} p<0.05,{ }^{\star \star} p<0.01,{ }^{\star \star \star} p<0.001$, and ${ }^{\star \star \star \star} p<0.0001$. 

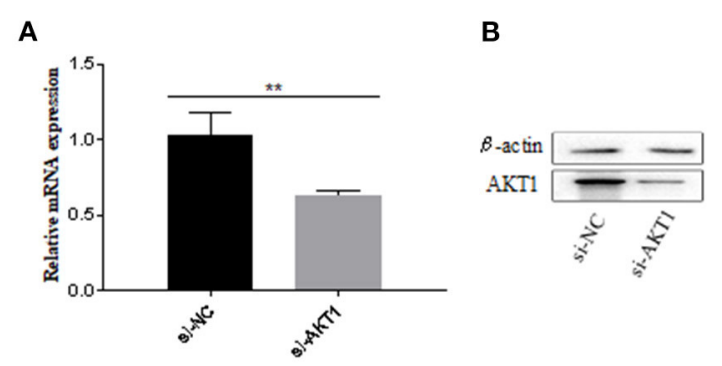

C

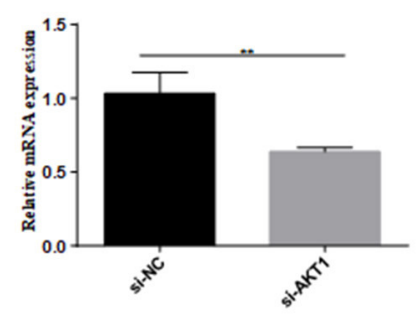

D

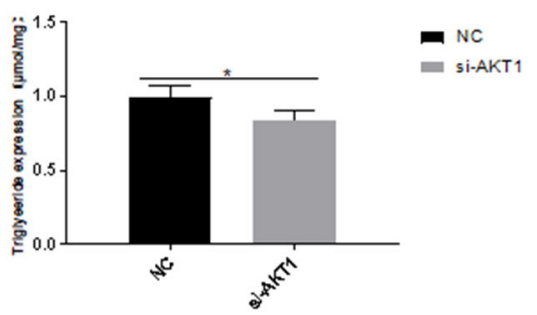

FIGURE 6 | Effects of AKT1 on the metabolism of adipocytes in Qinchuan cattle. (A) The efficiency of si-AKT1 transfection; (B,C) The expression levels of AKT1 mRNA and protein in pre-adipocytes transfected with si-AKT1 and negative control cells were compared; (D) After si-AKT1 treatment, the triglyceride level in pre-adipocytes decreased. Error bars represent mean \pm SD. $n=3$ replicates. "denotes significance according to Student's $t$-test, ${ }^{*} p<0.05,{ }^{* *} p<0.01$, and ${ }^{* \star *} p<0.001$.

triacylglycerol (TAG) levels in adipocyte precursors (Figure 6D), indicating that $A K T 1$ is a key transcription factor in preadipocytes from Qinchuan beef cattle.

\section{DISCUSSION}

We stained induced adipocytes with BODIPY on day 2 after differentiation and with Oil Red $\mathrm{O}$ on days 4 and 6 after differentiation. The number of lipid droplets was lower in the cells incubated with bta-miR-150 mimic than with mimic NC and higher in those incubated with miR-150 inhibitor than with inhibitor NC. These phenotypes remained consistent on days 2, 4 , and 6 of the induction of bovine adipocyte differentiation. Further experiments were based on this phenotype. The results confirmed that miR-150 functions in bovine fat formation, indicating that it is a candidate for the regulation of adipogenesis in cattle. At present, the precise role of miR-150 in the regulation of adipocyte differentiation remains unclear. Many previous studies used low-throughput methods, which cannot sufficiently explain the molecular regulatory mechanisms through which miR-150 affects the formation of pre-adipocytes. Therefore, we used high-throughput RNA-seq to identify DEG in adipocytes with overexpressed or inhibited miR-150. The results of KEGG enrichment analysis of the DEG in adipocytes incubated with inhibitor and inhibitor $\mathrm{NC}$ on day 2 implicated the mTOR pathway ( $p=0.0008$ ), because most genes in the pathway were changed due to miR-150 inhibition, and most of these DEG (such as INSR (Cignarelli et al., 2019), IGF1R (Hancock et al., 2019), RPS6KA1 (Song and Richard, 2015), and NFKB1 (Akbar et al., 2015) were related to "fat metabolism." To increase the richness of data analysis methods, we added the new WGCNA analysis (Langfelder and Horvath, 2008), which confirmed that among the multiple pathways enriched by DEG of five modules, the mTOR pathway was the most significant $(p=0.0092)$. Therefore, we verified that miR-150 mediates adipogenesis via the mTOR pathway. AKT1 is part of the mTOR pathway and was implicated as a target of miR-150. Western blotting and $\mathrm{qPCR}$ findings confirmed that $A K T 1$ functions during adipogenesis.
Protein phosphorylation is a common and important post-translational modification (Humphrey et al., 2015). Approximately a third of cellular proteins are thought to be phosphorylated, and mTOR is a typical phosphorylation pathway (Rausch et al., 2019). Mammalian TOR plays an essential role in the regulation of cell growth and metabolism, such as responding to cell nutrients and growth signals, and it is associated with diabetes (Saxton and Sabatini, 2017). The seed sequence of miR-150 will be combined with the $3^{\prime}$ region sequence of $A K T 1$. Qualcomm quantitative sequencing results have shown that when miR-150 is inhibited, insulin receptor substrates (IRS) are up-regulated, and receptor activation leads to the phosphorylation of key tyrosine residues on IRS proteins (Deng et al., 2020). After binding, the receptor activates p85 and recruits $\mathrm{p} 10$, which in turn catalyzes the generation of PI3P from PIP2 on the inner surface of the membrane. As the second messenger, PI3P further activates AKT and changes the phosphorylation level of AKT (Choi et al., 2010). Akt plays an important role in adipocyte differentiation ( $\mathrm{Xu}$ and Liao, 2004). The "molecular switch" of BSTA can promote AKT1 phosphorylation and promote adipocyte differentiation (Yao et al., 2013), whereas knocking out Akt1 affects insulinstimulated adipogenesis (Fischer-Posovszky et al., 2012). In addition, Akt1/Akt2-DKO mice have dyslipogenesis (Peng et al., 2003), and $A K T$ deficiency in adipocytes can lead to severe lipodystrophy (Shearin et al., 2016). We found that miR-150 seems to inhibit bovine pre-adipocyte differentiation, which might inhibit the mTOR signaling pathway.

\section{CONCLUSIONS}

Understanding the genetic basis of fat formation in beef cattle will support the breeding process to increase the intramuscular fat content of cattle. Our findings further validate and clarify the relationship between bta-miR-150 and bovine adipocyte differentiation; thus, overexpression of bta-miR-150 can inhibit adipocyte differentiation. Through RNA-seq sequencing data and WGCNA analysis methods, it was determined that the mTOR pathway, the signal pathway that plays a major role in bta-miR150 , affects bovine adipocytes' differentiation. This information 
paves the way for further research to elucidate the complex adipocyte differentiation and fat tissue production process.

\section{DATA AVAILABILITY STATEMENT}

The datasets presented in this study can be found in online repositories. The names of the repository/repositories and accession number(s) can be found below: NCBI SRA (accession: PRJNA684031).

\section{ETHICS STATEMENT}

All animal procedures for experiments were approved by Committee of Experimental Animal Management (EAMC) at Northwest A\&F University, China (protocol number: NWAFUCAST2018-168). Moreover, the use of experimental animals was carried out in accordance to the rules and guidelines of the organization and government. Written informed consent was obtained from the owners for the participation of their animals in this study.

\section{REFERENCES}

Akbar, H., Grala, T. M., Riboni, M. V., Cardoso, F. C., Verkerk, G., McGowan, J., et al. (2015). Body condition score at calving affects systemic and hepatic transcriptome indicators of inflammation and nutrient metabolism in grazing dairy cows. J. Dairy Sci. 98, 1019-1032. doi: 10.3168/jds.2014-8584

Ambele, M. A., Dhanraj, P., Giles, R., and Pepper, M. S. (2020). Adipogenesis: a complex interplay of multiple molecular determinants and pathways. Int. J. Mol. Sci. 21:4283. doi: 10.3390/ijms21124283

An, X., Ma, K., Zhang, Z., Zhao, T., Zhang, X., Tang, B., et al. (2016). miR17, miR-21, and miR-143 enhance adipogenic differentiation from porcine bone marrow-derived mesenchymal stem cells. DNA Cell Biol. 35, 410-416. doi: 10.1089/dna.2015.3182

Arcidiacono, B., Chiefari, E., Foryst-Ludwig, A., Curro, G., Navarra, G., Brunetti, F. S., et al. (2020). Obesity-related hypoxia via miR-128 decreases insulin-receptor expression in human and mouse adipose tissue promoting systemic insulin resistance. EBioMedicine 59:102912. doi: 10.1016/j.ebiom.2020.102912

Cai, R., Tang, G., Zhang, Q., Yong, W., Zhang, W., Xiao, J., et al. (2019). A novel lnc-RNA, named lnc-ORA, is identified by RNA-seq analysis, and its knockdown inhibits adipogenesis by regulating the PI3K/AKT/mTOR signaling pathway. Cells 8:477. doi: 10.3390/cells8050477

Choi, S. M., Tucker, D. F., Gross, D. N., Easton, R. M., DiPilato, L. M., Dean, A. S., et al. (2010). Insulin regulates adipocyte lipolysis via an Akt-independent signaling pathway. Mol. Cell. Biol. 30, 5009-5020. doi: 10.1128/MCB.00797-10

Chu, G., Zhou, X., Hu, Y., Shi, S., and Yang, G. (2019). Rev-erb $\alpha$ inhibits proliferation and promotes apoptosis of preadipocytes through the agonist GSK4112. Int. J. Mol. Sci. 20:4524. doi: 10.3390/ijms20184524

Cignarelli, A., Genchi, V. A., Perrini, S., Natalicchio, A., Laviola, L., and Giorgino, F. (2019). Insulin and insulin receptors in adipose tissue development. Int. J. Mol. Sci. 20:759. doi: 10.3390/ijms20030759

Deng, N., Guo, R., Zheng, B., Li, T., and Liu, R. H. (2020). IRS-1/PI3K/Akt pathway and miRNAs are involved in whole grain highland barley (Hordeum vulgare L.) ameliorating hyperglycemia of db/db mice. Food Funct. 11, 9535-9546. doi: 10.1039/D0FO01990A

Du, X., Hu, N., Yu, H., Hong, L., Ran, F., Huang, D., et al. (2020). miR-150 regulates endothelial progenitor cell differentiation via Akt and promotes thrombus resolution. Stem Cell Res. Ther. 11:354. doi: 10.1186/s13287-020-01871-9

Duarte, L., Garcia-Diaz, D. F., and Perez-Bravo, F. (2020). Body fat composition and miR-378 expression profiling in patients with type 1 diabetes. Ann. Pediatr. Endocrinol. Metab. 25, 118-125. doi: 10.6065/apem.1938088.044

\section{AUTHOR CONTRIBUTIONS}

XC, XM, SR, JW, XW, CL, and XY: conceptualization and data curation. XC, XM, SR, JW, CL, and XY: formal analysis. LZ: funding acquisition, project administration and supervision. $\mathrm{XC}$, SR, CM, and XW: investigation. CL: methodology. JW and LZ: resources. XM, SR, and XY: software. XC, XM, CM, and XW: validation. XC: writing - original draft. SR: writing - review \& editing. SS revised critically for content and grammar. All authors contributed to the article and approved the submitted version.

\section{FUNDING}

This research was funded by the National Key Research and Development Program of China (2018YFD0501700), National Natural Science Foundation of China (31972994), Key Research and Development Program of Ningxia Province (2019BEF02004), the National Beef and Yak Industrial Technology System (CARS-37), and the China Postdoctoral Science Foundation (2020T130540).

Fischer-Posovszky, P., Tews, D., Horenburg, S., Debatin, K. M., and Wabitsch, M. (2012). Differential function of Akt1 and Akt2 in human adipocytes. Mol. Cell. Endocrinol. 358, 135-143. doi: 10.1016/j.mce.2012.03.018

Hancock, M. L., Meyer, R. C., Mistry, M., Khetani, R. S., Wagschal, A., Shin, T., et al. (2019). Insulin receptor associates with promoters genome-wide and regulates gene expression. Cell 177, 722-736. doi: 10.1016/j.cell.2019.02.030

Humphrey, S. J., James, D. E., and Mann, M. (2015). Protein phosphorylation: a major switch mechanism for metabolic regulation. Trends Endocrinol. Metab. 26, 676-687. doi: 10.1016/j.tem.2015.09.013

Junjvlieke, Z., Khan, R., Mei, C., Cheng, G., Wang, S., Raza, S. H. A., et al. (2020). Effect of ELOVL6 on the lipid metabolism of bovine adipocytes. Genomics 112, 2282-2290. doi: 10.1016/j.ygeno.2019.12.024

Kang, M., Liu, X., Fu, Y., and Timothy Garvey, W. (2018). Improved systemic metabolism and adipocyte biology in miR-150 knockout mice. Metabolism 83, 139-148. doi: 10.1016/j.metabol.2017.12.018

Katz, Y., Wang, E. T., Airoldi, E. M., and Burge, C. B. (2010). Analysis and design of RNA sequencing experiments for identifying isoform regulation. Nat. Methods 7, 1009-1015. doi: 10.1038/nmeth.1528

Khan, R., Raza, S. H. A., Junjvlieke, Z., Wang, X., Wang, H., Cheng, G., et al. (2020). Bta-miR-149-5p inhibits proliferation and differentiation of bovine adipocytes through targeting CRTCs at both transcriptional and posttranscriptional levels. J. Cell. Physiol. 235, 5796-5810. doi: 10.1002/jcp. 29513

Khan, R., Raza, S. H. A., Junjvlieke, Z., Xiaoyu, W., Garcia, M., Elnour, I. E., et al. (2019). Function and transcriptional regulation of bovine TORC2 gene in adipocytes: roles of C/EBP $\gamma, \mathrm{XBP} 1, \mathrm{INSM} 1$ and ZNF263. Int. J. Mol. Sci. 20:4338. doi: 10.3390/ijms20184338

Kim, S. Y., Kim, A. Y., Lee, H. W., Son, Y. H., Lee, G. Y., Lee, J. W., et al. (2010). miR-27a is a negative regulator of adipocyte differentiation via suppressing PPAR $\gamma$ expression. Biochem. Biophys. Res. Commun. 392, 323-328. doi: 10.1016/j.bbrc.2010.01.012

Langfelder, P., and Horvath, S. (2008). WGCNA: an R package for weighted correlation network analysis. BMC Bioinformatics 9:559. doi: 10.1186/1471-2105-9-559

Liang, Y., Wang, Y., Ma, L., Zhong, Z., Yang, X., Tao, X., et al. (2019). Comparison of micro RNA $s$ in adipose and muscle tissue from seven indigenous Chinese breeds and Yorkshire pigs. Anim. Genet. 50, 439-448. doi: 10.1111/age.12826

Lillehammer, M., Meuwissen, T. H., and Sonesson, A. K. (2011). A comparison of dairy cattle breeding designs that use genomic selection. J. Dairy Sci. 94, 493-500. doi: 10.3168/jds.2010-3518 
Liu, Z., Deng, Y., Li, T., Zhu, F., Zhou, X., and He, Y. (2020). The opposite functions of miR-24 in the osteogenesis and adipogenesis of adipose-derived mesenchymal stem cells are mediated by the HOXB7/beta-catenin complex. FASEB J. 34, 9034-9050. doi: 10.1096/fj.202000006RR

Ma, L., Wang, R., Wang, H., Zhang, Y., and Zhao, Z. (2020). Long-term caloric restriction activates the myocardial SIRT1/AMPK/PGC-1 $\alpha$ pathway in C57BL/6J male mice. Food Nutr. Res. 64. doi: 10.29219/fnr.v64.3668

Ma, X., Wei, D., Cheng, G., Li, S., Wang, L., Wang, Y., et al. (2018). Bta-miR-130a/b regulates preadipocyte differentiation by targeting PPARG and CYP2U1 in beef cattle. Mol. Cell. Probes 42, 10-17. doi: 10.1016/j.mcp.2018.10.002

Peng, X. D., Xu, P. Z., Chen, M. L., Hahn-Windgassen, A., Skeen, J., Jacobs, J., et al. (2003). Dwarfism, impaired skin development, skeletal muscle atrophy, delayed bone development, and impeded adipogenesis in mice lacking Akt1 and Akt2. Genes Dev. 17, 1352-1365. doi: 10.1101/gad.1089403

Poklukar, K., Candek-Potokar, M., Batorek Lukac, N., Tomazin, U., and Skrlep, M. (2020). Lipid deposition and metabolism in local and modern pig breeds: a review. Animal 10:424. doi: 10.3390/ani10030424

Rausch, S., Schollenberger, D., Hennenlotter, J., Stühler, V., Kruck, S., Stenzl, A., et al. (2019). mTOR and mTOR phosphorylation status in primary and metastatic renal cell carcinoma tissue: differential expression and clinical relevance. J. Cancer Res. Clin. Oncol. 145, 153-163. doi: 10.1007/s00432-018-2775-5

Raza, S. H. A., Kaster, N., Khan, R., Abdelnour, S. A., El-Hack, M. E. A., Khafaga, A. F., et al. (2020). The role of microRNAs in muscle tissue development in beef cattle. Genes 11:295. doi: 10.3390/genes11030295

Ren, L., Li, Q., Hu, X., Yang, Q., Du, M., Xing, Y., et al. (2020). A novel mechanism of bta-miR-210 in bovine early intramuscular adipogenesis. Genes 11:601. doi: 10.3390/genes11060601

Sanchez-Gurmaches, J., Martinez Calejman, C., Jung, S. M., Li, H., and Guertin, D. A. (2019). Brown fat organogenesis and maintenance requires AKT1 and AKT2. Mol. Metab. 23, 60-74. doi: 10.1016/j.molmet.2019.02.004

Saxton, R. A., and Sabatini, D. M. (2017). mTOR signaling in growth, metabolism, and disease. Cell 168, 960-976. doi: 10.1016/j.cell.2017.02.004

Scrutinio, D., Conserva, F., Passantino, A., Iacoviello, M., Lagioia, R., and Gesualdo, L. (2017). Circulating microRNA-150-5p as a novel biomarker for advanced heart failure: a genome-wide prospective study. J. Hear. Lung Transpl. 36, 616-624. doi: 10.1016/j.healun.2017.02.008

Shearin, A. L., Monks, B. R., Seale, P., and Birnbaum, M. J. (2016). Lack of AKT in adipocytes causes severe lipodystrophy. Mol. Metab. 5, 472-479. doi: 10.1016/j.molmet.2016.05.006

Song, J., and Richard, S. (2015). Sam68 regulates S6K1 alternative splicing during adipogenesis. Mol. Cell. Biol. 35, 1926-1939. doi: 10.1128/MCB.01488-14

Song, N. J., Chang, S. H., Kim, S., Panic, V., Jang, B. H., Yun, U. J., et al. (2018). PI3Ka-Akt1-mediated Prdm4 induction in adipose tissue increases energy expenditure, inhibits weight gain, and improves insulin resistance in diet-induced obese mice. Cell Death Dis. 9:876. doi: 10.1038/s41419-018-0904-3
Twayana, S., Legnini, I., Cesana, M., Cacchiarelli, D., Morlando, M., and Bozzoni, I. (2013). Biogenesis and function of non-coding RNAs in muscle differentiation and in Duchenne muscular dystrophy. Biochem. Soc. Trans. 41, 844-849. doi: 10.1042/BST20120353

Wang, L., Zhang, S., Cheng, G., Mei, C., Li, S., Zhang, W., et al. (2020). MiR-145 reduces the activity of PI3K/Akt and MAPK signaling pathways and inhibits adipogenesis in bovine preadipocytes. Genomics 112, 2688-2694. doi: 10.1016/j.ygeno.2020.02.020

Wang, Y., Mei, C., Su, X., Wang, H., and Zan, L. (2019). MEF2A regulates the MEG3-IO3 miRNA mega cluster-targeted PP2A signaling in bovine skeletal myoblast differentiation. Int. J. Mol. Sci. 20:2748. doi: 10.3390/ijms201 12748

$\mathrm{Xu}$, J., and Liao, K. (2004). Protein kinase B/AKT 1 plays a pivotal role in insulin-like growth factor-1 receptor signaling induced 3T3-L1 adipocyte differentiation. J. Biol. Chem. 279, 35914-35922. doi: 10.1074/jbc.M402297200

Yao, Y., Suraokar, M., Darnay, B. G., Hollier, B. G., Shaiken, T. E., Asano, T., et al. (2013). BSTA promotes mTORC2-mediated phosphorylation of Akt1 to suppress expression of FoxC2 and stimulate adipocyte differentiation. Sci. Signal. 6:ra2. doi: 10.1126/scisignal.2003295

Yugawa, K., Yoshizumi, T., Mano, Y., Itoh, S., Harada, N., Ikegami, T. et al. (2020). Cancer-associated fibroblasts promote hepatocellular carcinoma progression through downregulation of exosomal miR-150-3p. Eur. J. Surg. Oncol. doi: 10.1016/j.ejso.2020.08.002

Zhang, L., Wu, Z. Q., Wang, Y. J., Wang, M., and Yang, W. C. (2020). MiR-143 regulates milk fat synthesis by targeting smad3 in bovine mammary epithelial cells. Animal 10:1453. doi: 10.3390/ani10091453

Zhang, Y. Y., Wang, H. B., Wang, Y. N., Wang, H. C., Zhang, S., Hong, J. Y., et al. (2017). Transcriptome analysis of mRNA and microRNAs in intramuscular fat tissues of castrated and intact male Chinese Qinchuan cattle. PLoS ONE 12:e0185961. doi: 10.1371/journal.pone.0185961

Zhang, Z., Wang, W., Liu, J. B., Wang, Y., Hao, J. D., Huang, Y. J., et al. (2020). ssc-miR-204 regulates porcine preadipocyte differentiation and apoptosis by targeting TGFBR1 and TGFBR2. J. Cell Biochem. 121, 609-620. doi: $10.1002 /$ jcb. 29306

Conflict of Interest: The authors declare that the research was conducted in the absence of any commercial or financial relationships that could be construed as a potential conflict of interest.

Copyright (C) 2021 Chen, Raza, Ma, Wang, Wang, Liang, Yang, Mei, Suhail and Zan. This is an open-access article distributed under the terms of the Creative Commons Attribution License (CC BY). The use, distribution or reproduction in other forums is permitted, provided the original author(s) and the copyright owner(s) are credited and that the original publication in this journal is cited, in accordance with accepted academic practice. No use, distribution or reproduction is permitted which does not comply with these terms. 